\title{
The Truth is Usually Somewhere in the Middle: Introduction to the Debate on Medical Marijuana
}

\author{
Elizabeth Dale Gilley*
}

Research Review Analyst, Founder of The Elle Foundation

\author{
*Corresponding author \\ Elizabeth Dale Gilley, Research Review Analyst, Founder of The Elle \\ Foundation. E-mail: gilley.elizabeth@yahoo.com
}

Submitted: 21 Apr 2018; Accepted: 28 Apr 2018; Published: 09 May 2018

As the national and global opioid epidemic worsens, as more of our children are found dead from heroin and/or opioid overdose, both an angry public and some branches of government turn an eye of accusation on Big Pharma, demanding restitution and money to offset the raising costs of combating this epidemic. President Trump has even voiced "Death to drug dealers!" Does this climate intensify emotional response during the medical marijuana debate? Let us open our minds to science, our hearts to compassion.

These are changing times. The old war on drugs has morphed, rightly so, into a war for recovery! We are self-correcting. The Addiction Recovery Industry is asked to let go of old perceptual frames which are outdated and no longer serve our best interests. As we turn our attention to the cutting edge of the scientific evidence base, let us consider the merit of perspective from arguments on both sides of the issue. Let us keep in mind that our goals should be to gain larger perspective, provide new therapeutic resource opportunity, efficient access for patients who may benefit from marijuana therapy, and be alert for increased risk for potential dependence to protect those who could be harmed.

Unlike many plants which have been used since antiquity for various medicinal purposes, Cannabis sativa, or marijuana as it is more commonly known may have been misjudged in the past, due to misunderstanding, or even political and economic agenda. As the debate over medical marijuana ensues, focus upon science reveals a growing evidence base of therapeutic benefit, ranging from the treatment of pain, to the moderation of negative side effects of chemotherapy. More recent research concludes that some isolated Cannabis sativa compounds, THC, short for Delta 9 Tetrahydro cannabinol and/or the non-psycho-active metabolite cannabidiol (CBD), when used in proper concentration, have correlation with the reduction in growth and size of cancerous tumors [1].

The Cannabis sativa plant has many variations, many compounds, hundreds which have not been researched. There are many strands of marijuana, cultivated from Hemp for its potency. We, the scientific research community, know very little about these. Much more research is needed: rigorous science, double blind trials, longitudinal studies, etc. Marijuana research has evolved from "in vitro," and/or animal studies, to human clinical trials. The longitudinal Adolescence Brain Cognitive Development Study (2017) of the effects of marijuana on developing brains enters its second year of operation. The National Library of Medicine (2017) provides a list of approved human clinical trials in the United States [2]. Consult the World Health Organization for information on national and/or international studies being conducted outside of the United States.

Homo sapien and evolving Homo noeticus have Cannabis receptor sights on the neural cell wall. Psychoactive properties of THC act upon the Central Nervous System (CNS), potentially resulting in changes in mood and consciousness, by stimulating and/or inhibiting neurotransmission [3]. Effects are extremely subjective, with THC and even CBD affecting individuals differently [4]. Intention plays a role also. Is the intention to heal, to center, or to zone out? The opposition for the legalization of marijuana for medical and recreational purposes claims that marijuana may lead to brain impairment, lower IQ scores, impaired cognition, memory, judgement and learning. They may be correct, especially for those whose brains are still developing.

However, the result from such research is not generalizable to the greater population as a whole. The results are only significant for those specific individuals who participated in the study. We must remember and utilize the scientific principles which form the foundation of credibility of our science. What is true for the masses is not always true for the individual, and what is true for individuals is not always true for the whole.

There are many population variables which cannot be controlled for in research design: genetic, epigenetic, environmental and/ or experiential variables. Depending upon the interaction of genetic and environmental influence, some individuals do in fact experience adverse reactions, worsening of mental health issues, including psychosis, panic attacks, the initiation of bi-polar disorder fluctuations, and the aggravation of schizophrenia [5]. Clearly not all individuals will be candidates for marijuana therapy.

Current peer reviewed research within the past five years, finds support for therapeutic benefit of the Cannabis compounds THC and/or CBD for the following:

1. Alzheimer's Disease,

2. Parkinson's Disease,

3. Multiple Sclerosis, 


\author{
4. Cancer, \\ 5. Adverse affects and effects of Chemotherapy, \\ 6. Epilepsy, \\ 7. Glaucoma, \\ 8. Anxiety, \\ 9. Depression, \\ 10. Hepatitis C, \\ 11. Opioid Addiction, \\ 12. Substance Use Disorder, \\ 13. Migraine, \\ 14. Fibromyalgia, \\ 15. Irritable Bowel Syndrome, \\ 16. Wound treatment, \\ 17. Morning sickness,
}

This is the short list, not a comprehensive list of all known marijuana therapeutic applications! Clearly marijuana has medicinal therapeutic benefit [6-12].

Research into the benefits of marijuana continues to increase exponentially, excitingly, expanding the scientific knowledge base. Importantly for our industry, research of dysfunction of abnormal action potential within the basil ganglia continues [13]. As potentially promising as this all sounds, it has been pointed out (rather ironically) by those who oppose the legalization that all this research has yet to pass the test of time and scientific rigor, by building the data base of longitudinal studies which may support and concur, or disprove earlier research hypotheses [14]. For decades, the National Institutes of Health and associated organizations have built a platform, which not only controls information, it markets perspective. Will the research studies supporting the health benefits of marijuana find equal exposure? [15].

Some are concerned that legalization of marijuana and making it freely available will worsen the drug addiction problem. Cutting edge addiction recovery research perspective supports the premise that drugs are not the cause. They are the result. Addiction is not really about drugs, it is about brains [16-20]. Building upon the past fifty years of research into what is now known as Reward Deficiency Syndrome, there is no debate - at least not on the doctoral level in the scientific research arena [21]. The challenge before the addiction recovery industry of practitioners is to become informed, to get on the same page, and move forward. This should be the criteria from which the reconfiguration of the industry is founded. Reward Deficiency Syndrome is the disease. Addiction is one of its symptoms. Some are informed. Many are not.

Looking back in history, in previous centuries Hemp was a staple. The fibers from the plant were used to make rope, and clothing, while the leaves were smoked. Hemp was valued as sacred plant medicine for its medicinal purposes. How did we get here? How did the plant become illegal and demonized? Public prejudice against Cannabis sativa has been spawned by what we now to know to be, false, advertising slogans, such as "Pot is the gateway drug!" For which there is NO scientific support [22].

The interjection of (mistaken) theory into the mainstream perspective was a powerful tool in ousting President Carter who wanted to decriminalize marijuana in the 1970's. In that era, RJ Reynolds tobacco was preparing to manufacture marijuana cigarettes. Having purchased farmland in Venezuela to grow marijuana, they decided to name the pot cigarettes "High Point." They already produced the TOP rolling papers, which you may realize is pot spelled backwards. Liquor industry lobbyists jumped on the band-wagon to keep marijuana out of the competition. The prejudicial slogan set back the advancement of marijuana research 50 years during which time it was genetically modified to become seedless. Politics and profits are powerful motivators. With innovation, there is opportunity for money to be made with legal medical marijuana, in licensing, production, and distribution.

In the past, criminalization efforts solidified original addiction theory and its treatment response. The Marijuana Act of 1937 was initially concerned with taxation. During the Nixon era, when the hippie culture was a threat to the continuation of the Vietnam War, Congress passed the Controlled Substances Act of 1970, making marijuana possession illegal. As the war to end the devastation of social costs of drug abuse began, it evolved into a war on drugs, illegal drugs not legal pharmaceutical drugs. Pot may have been its scapegoat.

According to the Global Cannabis Commission Report, and the United Nations Office of Drugs and Crime (UNODC), in 2005, 160 million, or $4 \%$ of the adult population worldwide actively used marijuana [23]. The World Health Organization estimated that in 2013, there were 181.8 million non-medical users worldwide [24]. In the United States, citizens are voting, changing the law. Twentyfive out of fifty states have decriminalized marijuana for medicinal use. Some states have legalized it for recreational use. Pew Research Center has taken polls which reveal changing trends, finding that the majority of the population is now in support of legalization and de-criminalization, with $53 \%$ in favor, and $44 \%$ opposed, up from the 2005 numbers which showed only $32 \%$ in favor, while the then majority of $60 \%$ opposed.

In the United States, the federal government controls all rights to the plant. Under Federal law, possession is still illegal, except in cases of authorized medical research [25]. But they are not enforcing it. The Federal government appears to be graciously, sitting back, allowing states the leeway to let their people decide. There is still a bit of a stall, or slowdown in the bureaucratic realms as new procedure must be developed before it can be can implemented. It's all so new. We have to figure this out. State licensing to grow, develop and distribute pot appears to be granted on the basis of political favor, with many minority farmers speaking out in protest of not being allowed licensing to legally plant a crop.

Since no one can legally patent a plant (yet), pharmaceutical development is busy making synthetic cannabis, isolating compounds which they can duplicate. Two cannabinoids have already been approved by the FDA, Dronabinol and Nabilone, for the "prevention or treatment of chemotherapy-related nausea and vomiting" with profits going to Big Pharma [26]. Existing research studies deal with specific isolated compounds and concentrations of cannabis, and its metabolites. However, even obtaining medical marijuana for research purposes is difficult as NIDA controls the legal supply $[27,28]$. Problems of standardization do exist, with so many diverse variations of the plant, which has been breed to increase profits and produce higher concentrations of THC [29].

When we step outside the politics of debate, and return to "center," we are reminded that our motivation and intention is to help heal. In conclusion, I wish to reiterate that truth is usually somewhere in the 
middle. All perspectives are valid. Let us move beyond the duality and/or polarity of the debate, seeking the greater truth. Let us open the mind to awareness of a continuity of truth. Cannabis sativa is only one of many plants, which mankind has attempted to control, scapegoat or profit from, which have therapeutic value in treatment response to opioid addiction. Iboga tabernathe being another. This opioid epidemic is one of many through the millennia which has assaulted and accosted the wellbeing of humanity [30-37].

\section{References}

1. McNamee D (2015) "Cannabis reduces tumor growth in study" Medical News Today in press, Retrieved from http:/www. medicalnewstoday.com/articles/279571.php.

2. US National Library of Medicine (2017) http://www. Clinicaltrials.gov.

3. Mannucci C, Navarra M, Calapai F, Spegnolo E, Busardo F et al. (2017) Neurological aspects of medical use of cannabidiol CNS Neurol Disord Drug Targets 16: 541-553.

4. Pacula R, Powell D, Heaton P, Sevigny EL (2015) Assessing the effects of medical marijuana laws on marijuana use: The devil is in the details Journal of Policy Analysis and Management 34: 7-31.

5. Yucel M, Bora E, Lubman D, Solowij N, Brewer WJ et al. (2012) The impact of cannabis use on cognitive functioning in patients with schizophrenia: a meta-analysis of existing findings and new data in a first-episode sample Schizophr. Bull 38: 316-330.

6. Watt G, Karl T (2017) In vivo evidence for therapeutic properties of cannabidiol (CBD) for Alzheimer's disease. Front Pharmacol 8: 20.

7. Chagasm M, Zuardi A, Tumas V, Pena-Pereira M, Sobreira E et al. (2014) Effects of cannabidiol I the treatment of patients with Parkinson's disease: Anexploratory double-blind trial. Journal Psychopharmacocol 28: 1088-1098.

8. Leussink VI, Husseine L, Warnke C, Broussalis E, Hartung H et al. (2012) Symptomatic therapy in multiple sclerosis: The role of cannabinoids in treating spasticity Therapeutic Advances in Neurological Disorders 5: 255-266.

9. Becker W, Nagarkatti M, Nagarkatti P (2017) Delta-9 Tetrahydrocannbinol (THC) activation of cannabinoid receptors induces unique changes in the murine jut microbiome and associated indiction of myeloid-derived suppressor cells and Th17 cells. Journal of Immunology, 198(1 Supplement) 218.11.

10. Devinsky O, Cilio M, Cross H, Fernandez-Ruiz J, French J et al. (2014) Cannabidiol: Pharmacology and potential therapeutic role in epilepsy and other neuropsychiatric disorders Epilepsia 55: 791-802.

11. Baron EP (2015) Comprehensive review of medical marijuana, cannabinoids, and therapeutic implications in medicine and headache: What a long strange trip it's been. Headache 55: 885-916.

12. Maida V, Corban J (2017) Topical medical cannabis: A new treatment for wound pain - Three cases of pyoderma gangrenosum Journal of Pain and Symptom Management 54: $732-736$

13. Fernandez-Ruiz J, Moreno-Martet M, Rodriquez-Cueto C, Palomo-Garo C, Gomez-Canas M et al. (2011) Prospects for cannabinoid therapies in basal ganglia disorders. British Journal Pharmcol 163: 1365-1378.

14. Volkow N (2015) Researching marijuana for therapeutic purposes: The potential promise of cannabidiol (CBD). Dr.
Nora Volkow's blog/nih.gov

15. Philipsen N, Butler R, Simon-Waterman C, Artis J (2014) Medical marijuana: A primer on ethics, evidence and politics. The Journal for Nurse Practitioners, Special Focus: Legal Matters 10: 633-640.

16. Gilley ED (2018) The Evolution of Addiction Treatment: The disease is Reward Deficiency Syndrome (RDS) and addiction is its symptom. European Journal of Biomedical and Pharmacological Science 5: 161-166.

17. Gilley ED (2017) Integrating the Science of Addiction and the Science of Wellbeing (Condensed version). Journal of Alcoholism and Drug Dependence 5: 275-281.

18. Gilley ED (2017) Integrating the Science of Addiction and the Science of Wellbeing (Full article p 1-37). The Elle Foundation: West Palm Beach, FL. At https://www.ResearchGate.net and https://www.Facebook.com/ellefoundation.

19. Gilley ED (2013) Alternative Treatment Modalities aid and facilitate recovery from childhood abuse trauma, Post-Traumatic Stress Disorder, and Substance Abuse Disorder. The Elle Foundation: Winston-Salem, NC.

20. Gilley ED (2012) Creating Addiction. The Elle Foundation: Winston-Salem, NC. https://www.facebook.com/ellefoundation and Portofpalmbeachpost.com

21. Blum K, Braverman E, Holder J, Lubar J, Miller D et al. (2000) Reward Deficiency Syndrome: A biogenetic model for the diagnosis and treatment of impulsive, addictive and compulsive behaviors. Journal of Psychoactive Drugs 32: 1-112.

22. Watson S, Benson J, Joy J (2000) Marijuana and medicine: Assessing the science base: A summary of the 1999 Institute of Medicine Report. Arch Gen Psychiatry 57: 547-552.

23. Beckley Foundation (2014) Global Cannabis Commission Report - Marijuana use around the world. (Data taken from the United Nations Office of Drugs and Crime (UNODC) 2005).

24. World Health Organization (2016) The health and social effects of non-medical cannabis.

25. Mead A (2017) The legal status of cannabis (marijuana) and cannabidoid (CBD) under US law. Epilepsy Behav 70: 288-291.

26. Adolescent Brain Cognitive Development Longitudinal Study (2017). https://www.addictionresearch.nih.gov/abcd-study.

27. Rubens M (2014) Political and medical views on medical marijuana and its future. Social Work in Public Health 29: 121-131.

28. The National Institute on Drug Abuse (NIDA) (2017).

29. Sevigny E, Pacula R, Heaton P (2014) The effects of medical marijuana laws on potency. International Journal of Drug Policy, 25: 308-319.

30. Fasinu P, Phillips S, ElSohly M, Walker L (2016) Current status and prospects for cannabidiol preparations as new therapeutic agents Pharmacotherapy 36: 781-796.

31. Kapoor S (2013) The inhibitory effects of Cannabidiol on systematic malignant tumors. Journal of Pain and Symptom Management 45.

32. McCauley K (2009) Pleasure Unwoven. Institute of Addiction Studies.

33. National Bureau of Economic Research (2015) Do medical marijuana laws reduce addiction and deaths related to pain killers? Working paper no. 21345. Cambridge, MA: National Bureau of Economic Research.

34. Ramer R, Heinmann K, Merford J, Rohde H, Salamon A et al. (2013) COX-2 and PPAR-gamma confer cannabidiol-induced apoptosis of human lung cancer cells. Molecular Cancer 
Therapy 12: 69-82.

35. Sarlin E (2016) Study links medical marijuana dispensaries to reduced mortality from opioid overdose. NIDA notes. May $17,2016$.

36. Nora D Volkow, Ruben D Baler, Wilson M Compton, Susan RB Weiss (2014). Adverse effects of marijuana use. New England
Journal of Medicine 370: 2219-2227.

37. White J (2016) Abuse and dependence potential of Cannabis sativa and nabiximols $38^{\text {th }}$ Expert Committee on Drug Dependence, 2016, Agenda item 5.1, Cannabis Update, World Health Organization.

Copyright: (C2018 Elizabeth Dale Gilley. This is an open-access article distributed under the terms of the Creative Commons Attribution License, which permits unrestricted use, distribution, and reproduction in any medium, provided the original author and source are credited. 